\title{
Reproducibility of incremental maximal cycle ergometer testing in patients with restrictive lung disease
}

Darcy D Marciniuk, Rodney E Watts, Charles G Gallagher

\begin{abstract}
Background-Exercise testing has become an important tool in the diagnosis and treatment of restrictive lung disease. The reproducibility of variables measured during exercise testing was examined in subjects with stable restrictive lung disease.

Methods-Six subjects, who had never previously undergone exercise testing, each underwent three maximal incremental exercise studies on a bicycle ergometer conducted during a 28 day period.
\end{abstract}

Results-Data collected at rest, before exercise, were not significantly different during the three study days. Comparison of results at the end of the exercise tests from the three studies also revealed no evidence of a significant learning effect. Reproducibility of exercise performance by subjects was assessed by the coefficient of variation. The mean within subject coefficient of variation at the end of the exercise tests was $5 \cdot 6 \%$ for work rate, $7 \cdot 9 \%$ for exercise duration, and $9.5 \%$ for dyspnoea. The mean within subject coefficient of variation obtained at the end of the exercise tests was $5 \cdot 3 \%$ for oxygen uptake $\left(\mathrm{Vo}_{2}\right), 2 \cdot 5 \%$ for oxygen saturation $\left(\mathrm{SaO}_{2}\right), 4 \cdot 0 \%$ for heart rate (HR), $5 \cdot 5 \%$ for minute ventilation ( $\dot{V} E), 5 \cdot 8 \%$ for respiratory frequency (f), and $4 \cdot 6 \%$ for tidal volume (VT). The mean within subject coefficient of variation at $40 \%$ and $70 \%$ of maximal work rates for $\mathrm{Vo}_{2}$ was $5 \cdot 7 \%$ and $5 \cdot 6 \%$ respectively, for $\mathrm{SaO}_{2} 1 \cdot 3 \%$ and $1 \cdot 5 \%$, for HR $4 \cdot 8 \%$ and $4 \cdot 0 \%$, for VE $6 \cdot 3 \%$ and $6 \cdot 6 \%$, for $f 10 \cdot 1 \%$ and $7 \cdot 8 \%$, and for VT $6.0 \%$ and $4 \cdot 5 \%$.

Division of Pulmonary Medicine, Department of Medicine, University of Saskatchewan, Saskatoon, Saskatchewan, Canada

D D Marciniuk R E Watts C G Gallagher

Reprint requests to: Dr D D Marciniuk, Division of Pulmonary Medicine, Department of Medicine, Royal University Hospital, Saskatoon, Saskatchewan S7N 0X0, Canada

Received 3 December 1992 Returned to authors 27 April 1993 27 April 1993 18 May 1993

Accepted 25 May 1993
Conclusions-Variables measured during clinical exercise testing in subjects with restrictive lung disease are highly reproducible. No significant learning effect was found on repeated testing in subjects who had never previously undergone exercise testing.

(Thorax 1993;48:894-898)

Exercise testing in patients with restrictive lung disease has become an important tool in early diagnosis for assessing disability and evaluating responses to treatment. ${ }^{12}$ It is well established that patients with restrictive lung disease have impaired exercise tolerance, as shown by reduced peak oxygen uptake (peak $\dot{\mathrm{VO}}_{2}$ ) and reduced maximal work rate $\vec{\circ}$

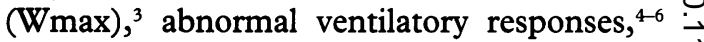
and a significant drop in arterial oxygen satu- $\vec{\omega}$ ration $\left(\mathrm{SaO}_{2}\right)$ during exercise. ${ }^{378}$ Despite the diagnostic and prognostic implications derived from these various responses, however, the reproducibility of these variables measured during clinical exercise testing has of not previously been examined in these $ᄋ$ patients. In order to assess its clinical significance we therefore studied the reproducibility 0 of incremental exercise tests in patients with restrictive lung disease. Both group mean and individual patient reproducibility of variables was assessed in patients with stable restrictive lung disease undergoing repeated incremental exercise studies conducted under identical circumstances.

\section{Methods}

PATIENTS

Characteristics of the study population are outlined in table 1. Subjects (five men and one woman) were recruited from the outpatient clinics of the Division of Respiratory Medicine. All subjects had clinical, radiographic, and pulmonary function testing evidence of restrictive lung disease, but no evidence of pulmonary restriction secondary to chest wall disease, pleural disease, or respiratory muscle weakness. Restrictive lung disease was the result of idiopathic pulmonary 9 fibrosis in three patients, sarcoidosis in two patients, and scleroderma in one patient; two were confirmed by open lung biopsy while $\stackrel{N}{\circ}$ one was confirmed by transbronchial lung biopsy. All subjects were clinically stable for at least two months before entering the study and had no rheumatological, neuromuscular, cardiac, peripheral vascular, or any disease apart from restrictive lung disease that might impair exercise tolerance. None of the sub-

Table 1 Mean (SD) characteristics of the study population $(n=6)$

\begin{tabular}{ll}
\hline Age (y) & $44(15)$ \\
TLC (l) & $4 \cdot 67(1 \cdot 01)(68 \%$ predicted) \\
VC (1) & $2 \cdot 83(0 \cdot 84)(57 \%$ predicted) \\
TLCO (\% predicted) & $57(22)$ \\
KCO (\% predicted) & $80(31)$ \\
FEV $_{1}$ & $2 \cdot 31(0 \cdot 52)(63 \%$ predicted) \\
FEV $_{1}$ /FVC & $83(8)$ \\
\hline
\end{tabular}

TLC - total lung capacity; VC-vital capacity; TLCotransfer factor; KCO-transfer coefficient; $\mathrm{FEV}_{1}$ - forced expired volume in one second; FVC-forced vital capacity. 
jects had previously undergone clinical exercise testing.

Pulmonary function was measured (SensorMedics 2200) in each subject before the start of the study. Forced expired volume in one second $\left(\mathrm{FEV}_{1}\right)$ and forced vital capacity (FVC) were measured using recommended techniques, ${ }^{9}$ lung volumes were obtained by the helium dilution method, and the carbon monoxide transfer factor (TLCO) was measured by the single breath technique. In order to calculate percentage predicted, the normal values of Morris and coworkers ${ }^{10}$ were used for spirometry, those of Goldman and Becklake ${ }^{11}$ for lung volumes, and those of Burrows and coworkers for transfer factor. ${ }^{12}$

The study was approved by the medical ethics committee of the University of Saskatchewan. All subjects gave informed consent to the procedures, but none was aware of the specific purpose of the study.

\section{PROTOCOL}

Before each exercise study $\mathrm{FEV}_{1}$ and FVC were measured with a pneumotachograph. At least three well coordinated maximal efforts were obtained and the highest value obtained for each variable was recorded. The subjects underwent a total of three exercise studies which were conducted during a 28 day period, each study separated by at least seven days. Exercise was performed in an air conditioned room and at the same time of day on each occasion. The subjects were asked to avoid strenuous activity on the day of testing and food or caffeinated drinks in the preceding two hours.

Testing was performed on an electrically braked cycle ergometer (Godart) while the subject breathed room air. After mounting the cycle ergometer and being attached to the mouthpiece, each patient rested quietly for two minutes before starting to pedal. A nose clip was used for all experiments. The initial exercise work load was $15 \mathrm{~W}$ and was increased by $15 \mathrm{~W}$ every minute of exercise until exhaustion. With the use of speedometer feedback each subject chose the pedalling rate within a range of 50-70 rpm. All subjects were instructed in an identical manner by the same operator for all exercise studies. The subjects were told that they should continue to exercise until they could exercise no more. No type of encouragement was offered and no communication was made with the subjects during the testing.

Electrocardiographic leads attached to the chest enabled continuous monitoring of the heart rate (HR) and electrocardiogram. $\mathrm{SaO}_{2}$ was monitored continuously by pulse oximetry (Nellcor 200). The mouthpiece was attached to a valve (Hans Rudolph Model No. 2730). Inspiratory flow and volume were measured by a standard inspiratory pneumotachograph/transducer/demodulator/integrator system using methods described previously..$^{13}$ The response of the system was linear over the range of inspiratory flows encountered in the study. The expired line was connected to a seven litre mixing cham- ber with baffles. Mean expired oxygen and carbon dioxide were analysed with a mass spectrometer (Airspec 2200). All equipment was calibrated before and after each exercise test. All signals were continuously displayed in real time on an eight channel recorder (Gould), and also stored on computer for later analysis.

\section{DATA ANALYSIS}

Minute ventilation ( $\dot{\mathrm{E}})$, tidal volume (VT), respiratory frequency (f), HR, oxygen uptake $\left(\mathrm{VO}_{2}\right)$, and carbon dioxide output $\left(\mathrm{V} \mathrm{CO}_{2}\right)$ were calculated over the last 30 seconds for each minute interval of exercise using standard formulae. ${ }^{14} \mathrm{VE}$ and VT were expressed at BTPS, $\dot{\mathrm{VO}}_{2}$ and $\dot{\mathrm{V}}_{\mathrm{CO}}$ were expressed at STPD. Predicted peak $\mathrm{VO}_{2}$ during exercise was calculated as ${ }^{14}$ :

Peak $\dot{\mathrm{VO}}_{2}=$

$$
0.83 \mathrm{ht}^{2.7} \times(1-0.007 \text { age }) \times(1-0.25 \mathrm{~S})
$$

where height (ht) is in metres and $S$ is a factor taking account of gender $(S=0$ for men and 1 for women). Predicted peak HR was calculated as ${ }^{14}$ :

$$
\text { Peak HR }=210-0.65 \text { age (years) }
$$

Sense of dyspnoea was assessed by the modified Borg scale ${ }^{15}$ at the end of exercise. All subjects were shown the Borg scale before exercise and familiarised with the scale. Subjects were then asked at the end of exercise: "How difficult is your breathing?" and asked to point with their finger to a number on the scale.

\section{STATISTICAL ANALYSIS}

Data collected at rest, at two matched submaximal work rates, and at the end of the exercise test were used in the analysis. The results used for the submaximal work rates were from work rates that most closely approximated $40 \%$ and $70 \%$ of $\mathrm{Wmax}$ from each subject's first exercise test. Comparisons were then made at matched work rates for the remaining studies.

Statistical significance of group mean data from the three experiment days was determined by repeated measures analysis of variance. The variability of subject results for the three experiments was assessed from the coefficient of variation. The coefficient of variation was derived by dividing the standard deviation by the mean. ${ }^{16}$ Analysis of the Borg scale was performed using Wilcoxon's signed rank test ${ }^{17} ; p<0.05$ was considered significant. The results are shown as mean (SD).

Analysis of our data showed that the sample size was sufficient to detect a $10 \%$ increase $(0 \cdot 141 / \mathrm{min})$ in peak $\mathrm{VO}_{2}$ between the first and third exercise studies with $91 \%$ power. ${ }^{18}$

\section{Results}

All subjects completed each exercise test without any complications and no exercise test was terminated by the physician. All data collected for the study were used in the analysis and no subjects were excluded. 
Table 2 Group mean (SD) values obtained at end of exercise

\begin{tabular}{|c|c|c|c|c|}
\hline & Test 1 & Test 2 & Test 3 & $p^{\star}$ \\
\hline Exercise duration (seconds) & $433(148)$ & $434(137)$ & $444(139)$ & NS \\
\hline Work rate $(W)$ & $118(36)$ & $120(30)$ & $120(38)$ & NS \\
\hline$\dot{\mathrm{VO}_{2}}(\mathrm{l} / \mathrm{min})$ & $1.39(0.37)$ & $1 \cdot 41(0.32)$ & $1 \cdot 39(0 \cdot 34)$ & NS \\
\hline $\mathrm{VCO}_{2}(1 / \mathrm{min})$ & $1.71(0.49)$ & $1.77(0.37)$ & $1.72(0.43)$ & NS \\
\hline $\mathrm{VE}(1 / \mathrm{min})$ & $60.9(18 \cdot 2)$ & $65 \cdot 3(17 \cdot 8)$ & $64.9(17 \cdot 1)$ & NS \\
\hline VT (1) & $1 \cdot 7(0 \cdot 2)$ & $1 \cdot 7(0.3)$ & $1 \cdot 7(0.3)$ & NS \\
\hline f (breaths $/ \mathrm{min}$ ) & $36(9)$ & $39(12)$ & $38(10)$ & NS \\
\hline $\mathrm{O}_{2}$ saturation $(\%)$ & $86(5)$ & $85(6)$ & $83(3)$ & NS \\
\hline HR (beats/min) & $148(9)$ & $150(5)$ & $146(12)$ & NS \\
\hline Borg scale & $4 \cdot 0(0.6)$ & $4 \cdot 8(1 \cdot 5)$ & $4 \cdot 7(1 \cdot 5)$ & NS \\
\hline
\end{tabular}

${ }^{\star} \mathrm{p}$ value for comparison of tests 1,2 , and 3 by analysis of variance; $\mathrm{VO}_{2}$-oxygen uptake $\mathrm{VCO}_{2}$ - carbon dioxide output; $\mathrm{VE}$ - minute ventilation; VT-tidal volume; $\mathrm{f}$ - respiratory frequency; HR-heart rate.

Figure 1 Mean (SD) values of the coefficient of variation for $\mathrm{VO}_{2}, \mathrm{SaO}_{2}$ and $H R$ measured at rest at end of exercise, and at submaximal work rates.
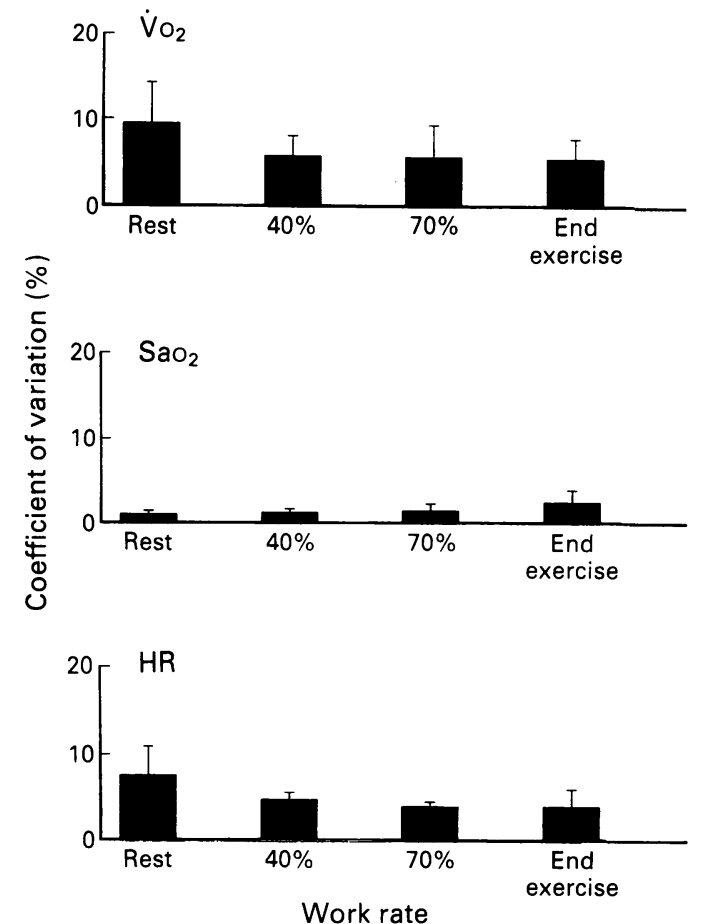

Figure 2 Mean (SD) values of the coefficient of variation for $V_{E}, V_{T}$, and $f$ measured at rest, at end of exercise, and at submaximal work rates.
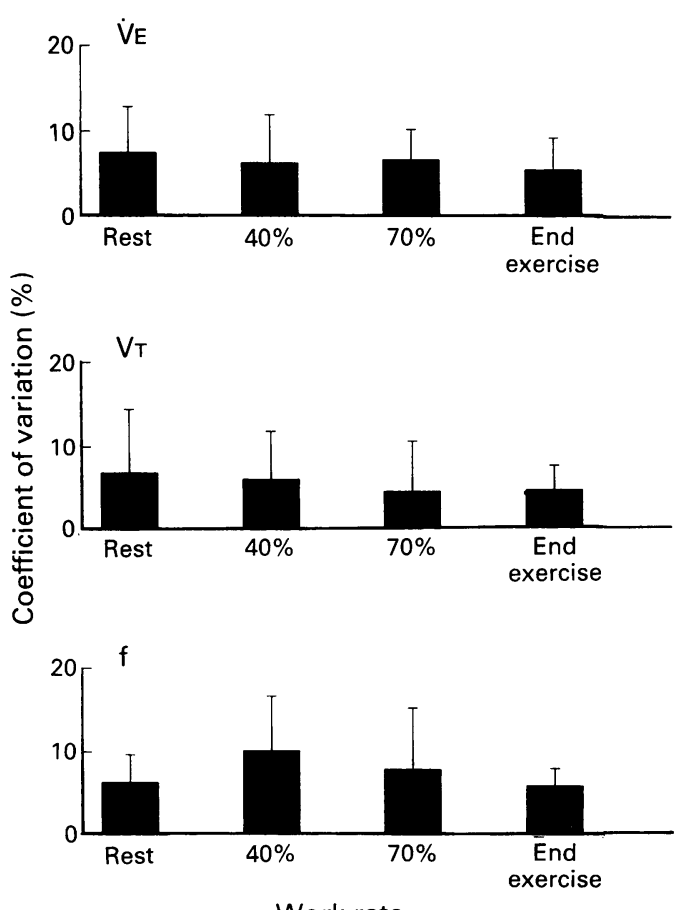

RESTING RESULTS

Analysis of group mean data collected at rest, immediately before exercise, revealed that spirometric values were not significantly different on any of the study days. The coefficient of variation for $\mathrm{FEV}_{1}$ was $3.5 \%$ (range음 $0 \cdot 4-10 \cdot 8 \%$ ) and for FVC was $3.4 \%$ (range 0.6-9.0\%). The mean resting $\mathrm{SaO}_{2}$ was $95 \%$ (range 90-99\%). In addition, values obtained $\stackrel{\oplus}{\rightarrow}$ at rest for $\dot{\mathrm{VO}}_{2}, \dot{\mathrm{V}} \mathrm{CO}_{2}, \dot{\mathrm{V}}, \mathrm{VT}, \mathrm{f}, \mathrm{SaO}_{2}$, and $\mathrm{HR} \frac{\mathrm{C}}{\mathrm{C}}$ were also not significantly different among $\frac{\bar{\sigma}}{\bar{\omega}}$ the three separate studies.

\section{EXERCISE RESULTS}

Exercise performance was impaired in all $\vec{\circ}$ subjects. The mean (SD) peak $\mathrm{VO}_{2}$ was $55 \% \overrightarrow{\vec{\omega}}$ $(10 \%)$ (range $41-68 \%$ ) of the age predicted normal value. The mean (SD) maximal HR was $81 \%(5 \%)$ of predicted. All subjects showed significant oxygen desaturation (mean (SD) $11 \%(5 \%)$, range 6-21\%). Theo ratio of peak $\dot{V}_{E}$ (mean of each subject's peak $\stackrel{\oplus}{\oplus}$ $\dot{V}_{E}$ obtained from the three exercise studies) to $\mathrm{FEV}_{1}$ was 28 (7) for the group (range $\vec{c}$ 17-35). Four subjects discontinued exercise $\mathbb{0}$ because of leg fatigue, while two subjects $\frac{\mathbb{\Phi}}{\mathbb{D}}$ stopped because of dyspnoea. Table 2 lists 3 group mean data collected at the end of the $\frac{\mathbb{D}}{\mathrm{C}}$ exercise test. There was no significant differ- $\overrightarrow{0}$ ence in exercise duration, work rate, or the peak $\dot{\mathrm{VO}}_{2}$ at end of exercise among the three studies. $\dot{\mathrm{V}}_{2}, \dot{\mathrm{V}}, \mathrm{VT}, \mathrm{f}, \mathrm{SaO}_{2}, \mathrm{HR}$, and Borg scores also did not differ among the three studies at end of exercise. In addition, there was no significant difference in these variables $\frac{\mathcal{Q}}{\mathbb{Q}}$ at $40 \% \mathrm{~W} \max$ and $70 \% \mathrm{Wmax}$. The mean $\overrightarrow{\vec{F}}$ work rate at $40 \% \mathrm{Wmax}$ was $43 \mathrm{~W}$ and at 을 $70 \%$ Wmax was $80 \mathrm{~W}$

\section{EXERCISE VARIABILITY}

The mean within subject coefficients of varia-음 tion for $\dot{\mathrm{VO}}_{2}, \mathrm{SaO}_{2}$, and $\mathrm{HR}$ as a function of work rate (\% Wmax) are presented in fig $1 . \frac{0}{3}$ Values obtained at rest and at end of exercise, as well as those measured at $40 \% \mathrm{Wmax}$ and 3 $70 \% \mathrm{Wmax}$, are shown. The mean within subject coefficients of variation at end of exercise for $\dot{\mathrm{VO}}_{2}$ was $5 \cdot 3 \%$ (5.3-9.5\% throughouto exercise), for $\mathrm{SaO}_{2}$ was $2 \cdot 5 \%(1 \cdot 1-2 \cdot 5 \%$ throughout exercise), and for $\mathrm{HR}$ was $4.0 \%$ \% (4.0-7.6\% throughout exercise). The mean 0 within subject coefficient of variation for the decrease in $\mathrm{SaO}_{2}$ during exercise was $17.3 \%$ (not shown in fig).

Figure 2 shows the mean within subject coefficients of variation for $\dot{\mathrm{V}}, \mathrm{VT}$, and for $\mathrm{f}, \stackrel{+}{+}$ also as a function of work rate. The mean $\frac{0}{0}$ within subject coefficients of variation for $\dot{\mathrm{E}} \frac{\mathrm{O}}{\mathrm{D}}$ at end of exercise was $5.5 \% \quad\left(5 \cdot 5-7 \cdot 5 \% \frac{O}{1}\right.$ throughout exercise), for VT was $4.6 \%$ 을 (4.4-6.8\% throughout exercise), and for was $5 \cdot 8 \%(5 \cdot 8-10 \cdot 1 \%$ throughout exercise).

Figure 3 shows the mean within subject coefficients of variation obtained at end of을 exercise for exercise duration, the Borg score, and for work rate. The mean within subject coefficient of variation for exercise duration was $7 \cdot 2 \%$ (range $2 \cdot 7-12 \cdot 3 \%$ ), for Borg scale was $9.5 \%$ (range $0-26.9 \%$ ), and for work rate was $5 \cdot 6 \%$ (range $0-13 \cdot 6 \%$ ). Individual results 
Figure 3 Mean (SD) values of the coefficient of variation for exercise duration, Borg score, and work rate measured at end of exercise.

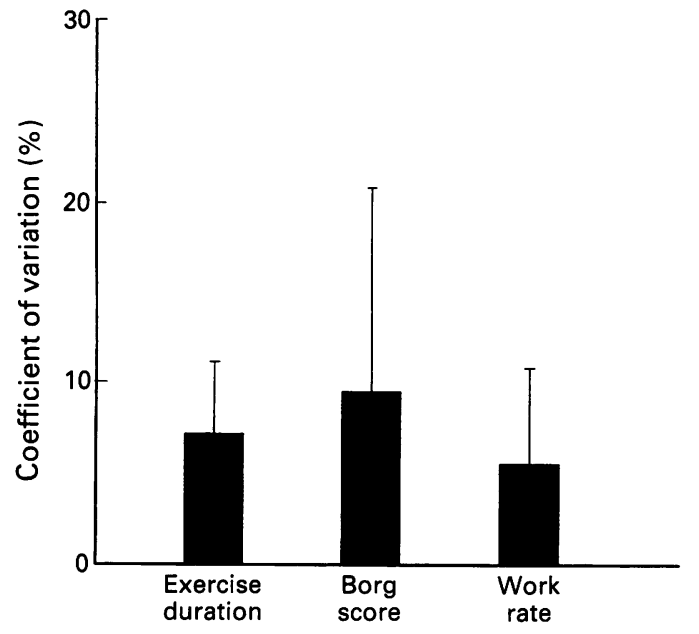

for $\dot{V}$ versus $\dot{V}_{2}$ in the three tests are plotted in fig 4 and show that the relationship between $\dot{\mathrm{V}}_{\mathrm{E}}$ and $\dot{\mathrm{VO}}_{2}$ is very similar in each subject's three tests.

\section{Discussion}

The reproducibility of clinical exercise testing in patients with restrictive lung disease has not previously been examined. However, numerous studies have examined the reproducibility in normal subjects, ${ }^{19} 20$ in patients with congestive heart failure, ${ }^{2122}$ and in patients with chronic airflow limitation. ${ }^{23-30}$ Garrard and Emmons ${ }^{19}$ found that values obtained during exercise testing in normal subjects were highly reproducible, although some diurnal variation was seen. On the other hand, in patients with stable congestive heart failure Elborn et $a l^{21}$ found that exercise time increased by $20 \%$ with repeated testing.

In patients with chronic airflow limitation undergoing repeated walking tests Knox and coworkers $^{30}$ found a significant increase in walking distances with repeated testing. Swinburn et al, ${ }^{25}$ in patients with severe chronic airflow limitation, found a $29 \%$ increase in performance with cycle ergometer testing between the first and fourth exercise tests. Conversely, Brown et $a{ }^{26}$ Cox and coworkers, ${ }^{29}$ Silverman and coworkers, ${ }^{27}$ and Muza et $a l^{28}$ found no significant learning effect with repeated exercise testing, and variability in measured variables ranged from 3\% to $12 \%$. More recently, Belman et $a^{24}$ found that, while the Borg scale ratings decreased with repeated testing, other variables stabilised after one or two practice attempts. However, except for the Borg ratings, only heart rate showed a significant change between the first and second tests, and heart rate showed no significant change between the second, third and fourth tests. Furthermore, no significant changes in oxygen uptake, minute ventilation, tidal volume, or respiratory frequency were seen between the four exercise studies, so the data appear to suggest that the reproducibility was good and no learning effect, even after the first study, was noted in these variables.

In view of the conflicting results in the literature for patients with other diseases, an accurate assessment of the variability of exercise testing in patients with restrictive lung disease was needed. Our results, in clinically stable patients who have not undergone previous cycle ergometer exercise testing, suggest that reproducibility is high. The reproducibility we noted during exercise was similar to the reproducibility we found in spirometric tests obtained before exercise. We also found no significant learning effect between the three studies, suggesting that practice exercise studies are not necessary in patients with restrictive lung disease even if they have not previously exercised on a cycle ergometer. Our protocol approximates the environment of clinical exercise testing laboratories and therefore enables the results to be clinically applicable.
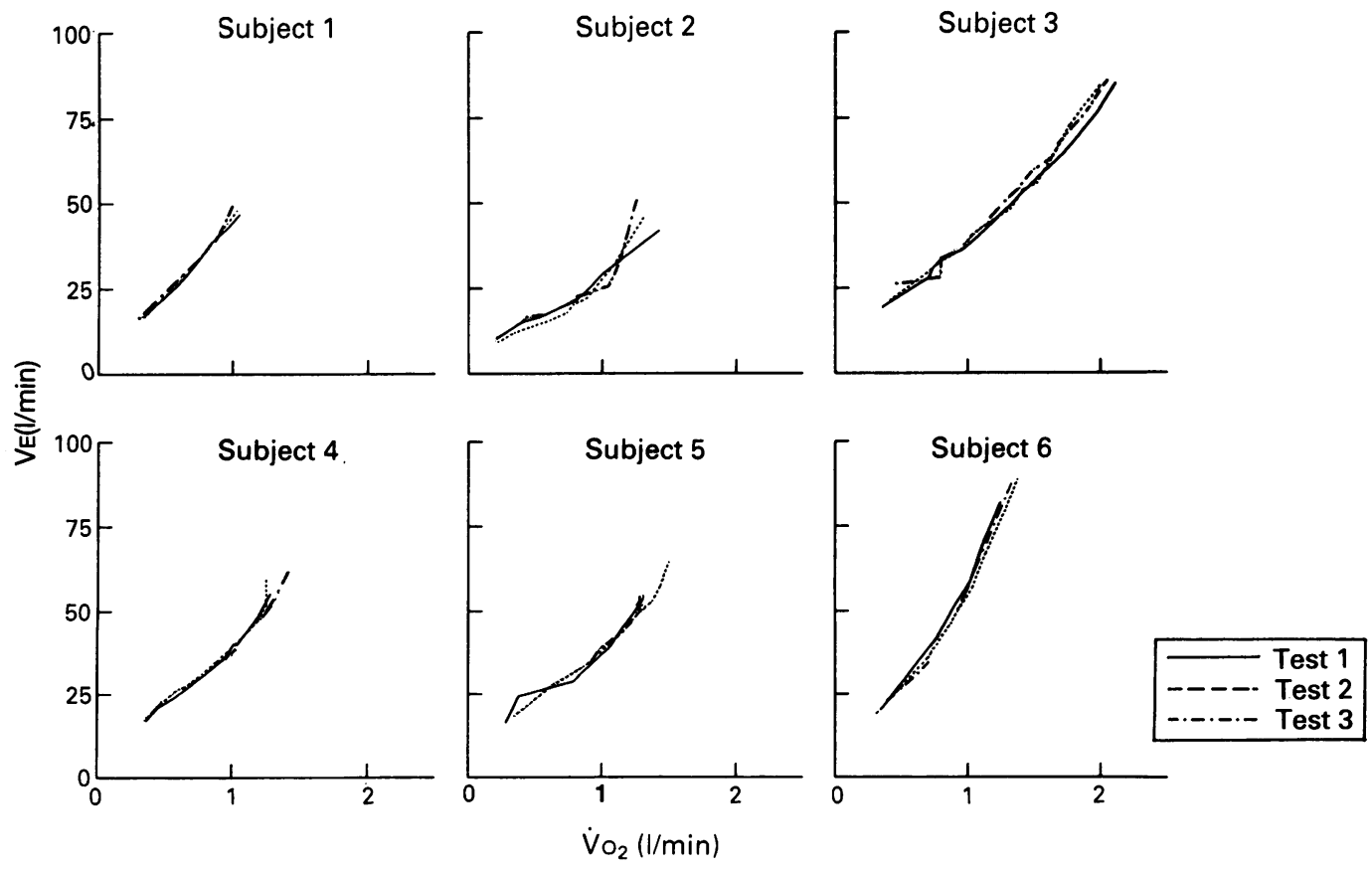

Figure 4 Individual results for $\dot{V}$ versus $\dot{V O}_{2}$ in the three tests. 
While measurements at maximal exercise are important, it is often equally important to examine variables measured during submaximal exercise, especially since many patients will stop exercise well below expected maximum values. ${ }^{14}$ Comparison of our results, measured at $40 \% \mathrm{Wmax}$ and $70 \% \mathrm{Wmax}$, shows that reproducibility at these submaximal levels of exercise parallels the reproducibility of measurements made at end of exercise. This suggests that, in addition to generating reproducible end of exercise measurements, measurements made at submaximal levels of exercise may also be used appropriately in evaluating the results of clinical exercise testing in these patients.

From this study we have found that measurements during clinical exercise testing in subjects with restrictive lung disease are highly reproducible and show no learning effect with successive studies. Clinical exercise testing can be reliably used to diagnose and monitor patients with restrictive lung disease.

We wish to thank Ms Candace Leuschen for her assistance in the preparation of the manuscript. The study was supported by the Saskatchewan Lung Association and by the Saskatchewan Health Research Board. Dr Marciniuk and Dr Gallagher are Saskatchewan Lung Association Scholars.

1 Kelly MA, Daniel RP. Exercise testing in interstitial lung disease. Clin Resp Med 1984;5:145-56.

2 Epler GR, Saber FA, Gaensler EA. Determination of severe impairment (disability) in interstitial lung disease. Am Rev Respir Dis 1980;121:647-59.

3 Spiro SG, Dowdeswell IRG, Clark TJH. An analysis of submaximal exercise responses in patients with sarcoidosis and fibrosing alveolitis. Br $\mathcal{F}$ Dis Chest 1981; 75:169-80.

4 Bye PTP, Anderson SD, Woolcock AJ, Young IH, Alison JA. Bicycle endurance performances of patients with interstitial lung disease breathing air and oxygen. $\mathrm{Am}$ Rev Respir Dis 1982;126:1005-12.

5 Burdon JGW, Killian KJ, Jones NJ. Pattern of breathing during exercise in patients with interstitial lung disease. Thorax 1983;38:778-84.

6 Jones NL, Rebuck AS. Tidal volume during exercise in patients with diffuse fibrosing alveolitis. Bull Eur Physiopathol Respir 1979;15:321-7.

7 Denison D, Al-Hillawi H, Turton C. Lung function in interstitial lung disease. Semin Respir Med 1984;6:40-54.

8 Keogh BA, Lakatos E, Price D, Crystal RG. Importance of the lower respiratory tract in oxygen transfer. $\mathrm{Am} \mathrm{Rev}$ Respir Dis 1984;129(Suppl):S76-80.

9 Gardner RM, Hankinson JL, Clauson JL, Crapo RO, Johnson RL Jr, Epler GR. American Thoracic Society standardization of spirometry-1987 update. Am Rev Respir Dis 1987;136:1285-98.

10 Morris JF, Koski A, Johnson LC. Spirometric standards for healthy non-smoking adults. Am Rev Respir Dis 1971;103:57-67.

11 Goldman HI, Becklake MR. Respiratory function tests: normal values at median altitudes and the prediction of normal results. Am Rev Tuberc Pulm Dis 1959;79: 457-67.

12 Burrows B, Kasik JE, Niden AH, Barclay WR. Clinical ? usefulness of the single-breath pulmonary diffusing capacity test. Am Rev Respir Dis 1961;84:789-806.

13 Gowda K, Zintel T, McParland C, Orchard R, Gallagher $\overline{0}$ CG. Diagnositic value of maximal exercise tidal volume. Chest 1990;98:1351-4.

14 Jones NL. Clinical exercise testing. Philadelphia: Saunders, $\frac{\bar{\sigma}}{\supset}$

1988.
15 Borg G. Psychophysical bases of perceived exertion. Med $\frac{\Phi}{\overparen{\Phi}}$ Sci Sports Exerc 1982;14:377-81.

16 Snedecor GW, Cochran WG. Statistical methods. 8th edn. $\overrightarrow{0}$ Ames, Iowa: Iowa State University Press, 1989:26-7.

17 Dixon WJ, Massey FJ. Introduction to statistical analysis. $\overrightarrow{\vec{H}}$ 4th edn. New York: McGraw-Hill, 1983:391-2.

18 Snedecor GW, Cochran WG. Statistical methods. 8th edn. S Ames, Iowa: Iowa State University Press, 1989:38-53.

19 Garrard CS, Emmons C. The reproducibility of the respiratory responses to maximum exercise. Respiration $\stackrel{\oplus}{\infty}$ 1986;49:94-100

20 Wilson RC, Jones PW. Long-term reproducibility of Borg scale estimates of breathlessness during exercise. Clin Sci 1991;80:309-12.

21 Elborn JS, Stanford CF, Nicholls DP. Reproducibility of 윽 cardiopulmonary parameters during exercise in patients with chronic cardiac failure. The need for a preliminary $C S$ test. Eur Heart f 1990;11:75-81.

22 Janicki JS, Gupta S, Ferris ST, McElroy PA. Long-term reproducibility of respiratory gas exchange measure- $\frac{1}{3}$ ments during exercise in patients with stable cardiac failure. Chest 1990;97:12-7.

23 Owens MW, Kinasewity GT, Strain DS. Evaluating the effects of chronic therapy in patients with irreversible 0 air-flow obstruction. Am Rev Respir Dis 1986;134: $\omega$ 935-7.

24 Belman MJ, Brooks LR, Ross DJ, Mohsenifar Z. Variability of breathlessness measurement in patients with chronic obstructive pulmonary disease. Chest 1991;99:566-71.

25 Swinburn CR, Wakefield JM, Jones PW. Performance, 음 ventilation, and oxygen consumption in three different $\stackrel{\mathbb{Q}}{\varrho}$ types of exercise test in patients with chronic obstructive $\vec{F}$ lung disease. Thorax 1985;40:581-6.

26 Brown SE, Fisdor CE, Steinsburg DW, Light RW. Reproducibility of $\mathrm{VO}_{2} \max$ in patients with chronic airflow obstruction. Am Rev Respir Dis 1985;131:435-8.

27 Silverman M, Barry J, Hellerstein H, Janos J, Kelsen S. Variability of the perceived sense of effort in breathing during exercise in patients with chronic obstructive pulmonary disease. Am Rev Respir Dis 1988;137:206-9.

28 Muza SR, Silverman MT, Gilmore GC, Hellerstein HK, Kelsen SG. Comparison of scales used to quantitate the $\overline{3}$ sense of effort to breathe in patients with chronic. obstructive pulmonary disease. Am Rev Respir Dis 1990;141:909-13.

29 Cox NIM, Hendriks JCM, Binkhorst RA, Folgering HT, van Herwaarden CLA. Reproducibility of incremental maximal cycle ergometer tests in patients with mild to $D$ moderate obstructive lung diseases. Lung 1989;167:을.

30 Knox AJ, Morrison JFJ, Muers MF. Reproducibility of $N$ walking test results in chronic obstructive airways disease. Thorax 1988;43:388-92. 